\title{
PLENARY
}

P01 TRENDS IN PAEDIATRIC COELIAC DISEASE 1990-2009: A UK REGIONAL RETROSPECTIVE AUDIT OF CASES

${ }^{1}$ LE White, ${ }^{2}$ VMW Merrick, ${ }^{1} E$ Bannerman, ${ }^{3} \mathrm{DC}$ Wilson, ${ }^{4} \mathrm{R}$ Russell, ${ }^{5} \mathrm{D}$ Basude,

${ }^{2,3}{ }^{3}$ Henderson, ${ }^{2} \mathrm{PM}$ Gillett ${ }^{1}$ Department of Dietetics, Nutrition and Biological Sciences, Queen Margaret University, Edinburgh, UK; ${ }^{2}$ Department of Paediatric Gastroenterology, Hepatology and Nutrition, Royal Hospital for Sick Children Edinburgh, Edinburgh, UK; ${ }^{3}$ Child Life and Health, University of Edinburgh, Edinburgh, UK; ${ }^{4}$ Department of Paediatric Gastroenterology, Hepatology and Nutrition, Royal Hospital for Sick Children Glasgow, Glasgow, UK; ${ }^{5}$ Department of Paediatric Gastroenterology, Hepatology and Nutrition, Bristol Children's Hospital, Bristol, UK

10.1136/archdischild-2012-301885.1

Aim To review all incident cases of paediatric coeliac disease (CD) in a UK region over the 20 year period from 1990-2009; to observe trends in incidence, symptom presentation, age at diagnosis and the impact of active screening of at-risk groups; and to audit laboratory results at diagnosis for 01/2005-12/2009.

Methods We performed a retrospective audit of case notes, pathology databases, endoscopy and electronic patient records for all children under 16 years diagnosed with $C D$ on duodenal biopsy between $01 / 1990$ and $12 / 2009$ in a UK region of 1.25 million population, of whom 233,000 were aged $<16$ years of age.

Results 266 biopsy positive children were diagnosed during the 20 year study period with a mean increase in age-sex standardised incidence from 1.76 (95\% CI 1.08-2.72) to 11.74 (95\% CI 9.82-13.93) per 100,000 aged <16 years in the 1990-1994 and 2005-2009 epochs respectively $(\mathrm{p}=0.001)$. The median (IOR) age at diagnosis also increased significantly from 29 (16-53.25) months to 90 (53.5-132.5) months in 1990-1994 and 2005-2009 epochs respectively $(p<0.0001) .21 \%$ of children presented non-classically in 2005-2009 compared to 5\% in 1995-1999 $(p=0.008)$; this included children presenting monosymptomatically with one isolated gastrointestinal (GI) symptom and those with extra-intestinal symptoms. $7 \%$ of children were diagnosed through targeted screening in 1990-1994 compared to $23 \%$ in $2005-2009$ ( $p=0.002)$. Routine blood investigations demonstrated that over $25 \%$ were anaemic and over $50 \%$ were iron deficient at presentation in 2005-2009.

Conclusions The incidence of paediatric $\mathrm{CD}$ has increased seven-fold over the last 20 years in a UK region. Children are older at diagnosis, presenting with fewer GI symptoms, and with iron deficiency anaemia remaining the commonest laboratory abnormality. We suggest that this increase in incidence is largely due to both increased screening of at risk groups and a lower threshold for investigating for $C D$ as a result of greater clinician awareness of the condition's heterogenic nature. A UK-wide study would be beneficial to identify national trends in incidence and symptomatology. 
ADC

\section{Trends in paediatric coeliac disease 1990-2009: a UK regional retrospective audit of cases}

LE White, VMW Merrick, E Bannerman, et al.

Arch Dis Child 2012 97: A1

doi: 10.1136/archdischild-2012-301885.1

Updated information and services can be found at:

http://adc.bmj.com/content/97/Suppl_1/A1.1

These include:

Email alerting Receive free email alerts when new articles cite this article. Sign up in service the box at the top right corner of the online article.

$\begin{array}{cc}\text { Topic } & \text { Articles on similar topics can be found in the following collections } \\ \text { Collections } & \text { Screening (epidemiology) (288 articles) } \\ \text { Screening (public health) (288 articles) } & \text { Pathology (120 articles) } \\ \text { Clinical diagnostic tests (504 articles) } \\ \text { Metabolic disorders (434 articles) } \\ \text { Radiology (433 articles) } \\ \text { Surgery (144 articles) } \\ \text { Surgical diagnostic tests (137 articles) } \\ \text { Malnutrition (91 articles) }\end{array}$

Notes

To request permissions go to:

http://group.bmj.com/group/rights-licensing/permissions

To order reprints go to:

http://journals.bmj.com/cgi/reprintform

To subscribe to BMJ go to:

http://group.bmj.com/subscribe/ 